\title{
Zeichen und Abkürzungen
}

\section{Bedeutung von Zeichen}

() In runde Klammern gesetzt sind

- bei Zeitschriften: die Jahrgangsangaben vor dem Erscheinungsjahr;

- bei Bänden einer Reihe: Titel und Bandzahl der Reihe;

- bei im Druckwerk fehlenden bibliographischen Angaben: die anderweitig ermittelten entsprechenden Angaben.

[ ] Die eckigen Klammern schließen ergänzende Hinzufügungen ein, z.B.

- in Monographien Seitenangaben von Abschnitten zur Gefängnisseelsorge;

- Veröffentlichung des Beitrages, ggf. unter anderem Titel, auch in einer anderen Publikation.

< Die Winkelklammern im Hauptsachtitel schließen Angaben zur Übersetzung der Originalausgabe ein. Anmerkung: In kursiv gedruckten Winkelklammern stehen die Sondersigel zum Verweis auf Fachbibliotheken, vgl. Sigelübersicht und Sigelverzeichnis.

| Der senkrechte Strich dient zur Trennung von bibliographischer Eintragung und Sigel.

* Das einer Eintragung vorangestellte Sternchen bezeichnet ein Sammelwerk mit gesonderter Eintragung von Einzeltitel(n).

- Das Gradzeichen verweist bei Sammelwerken im Anschluß an die Titelbeschreibung auf in abgekürzter Form gesondert eingetragene Einzeltitel.

\section{Abkürzungen von Zeitschriften}

$\begin{array}{ll}\text { BewHi } & \text { Bewährungshilfe } \\ \text { EvTh } & \text { Evangelische Theologie } \\ \text { JR } & \text { Juristische Rundschau } \\ \text { MPTh } & \text { Monatsschrift für Pastoraltheologie } \\ \text { MschrKrim } & \text { Monatsschrift für Kriminologie und Strafrechtsreform } \\ \text { NStZ } & \text { Neue Zeitschrift für Strafrecht } \\ \text { WzM } & \text { Wege zum Menschen } \\ \text { ZEE } & \text { Zeitschrift für Evangelische Ethik } \\ \text { ZevKR } & \text { Zeitschrift für evangelisches Kirchenrecht } \\ \text { ZFStrVo } & \text { Zeitschrift für Strafvollzug und Straffälligenhilfe }\end{array}$

